\title{
A Review of Monitoring Construction Equipment in Support of Construction Project Management
}

\author{
Yutaro Nakanishi *, Takashi Kaneta and Sayaka Nishino \\ Department of Architecture and Architectural Engineering, Kyoto University, Kyoto, Japan
}

OPEN ACCESS

Edited by:

Zhen Chen,

University of Strathclyde,

United Kingdom

Reviewed by:

John Schaufelberger,

University of Washington,

United States

Aviad Shapira,

Technion Israel Institute of

Technology, Israel

*Correspondence:

Yutaro Nakanish

nakanishi_crcl_yutaro@yahoo.co.jp

Specialty section:

This article was submitted to Construction Management,

a section of the journal

Frontiers in Built Environment

Received: 23 November 2020 Accepted: 20 December 2021

Published: 19 January 2022

Citation:

Nakanishi $Y$, Kaneta T and Nishino S (2022) A Review of Monitoring Construction Equipment in Support of

Construction Project Management.

Front. Built Environ. 7:632593.

doi: 10.3389/fbuil.2021.632593
Progress monitoring is an important aspect of construction project control that is fundamental to proper project management and decision-making. Traditional monitoring methods are inaccurate, time-consuming, and labor-intensive because they rely on large-scale manual operations. The defect of the method has been identified as one of the major problems causing project delays and cost overruns. In recent years, a variety of emerging automated data collection, analysis, and visualization techniques have been used to establish methods for digitized, realtime progress monitoring, and there are several papers that address these methodologies and comprehensive reviews. Among them, the authors conducted a review of various studies focusing on how to apply the monitoring of construction equipment to project management. The authors selected the studies of interest using research databases such as Google Scholar and ScienceDirect. Then, the authors classified those studies by technology, purpose, and subject matter, and analyzed the details. Through a literature review, it was revealed that most of the studies were focused on digitalization and review of the lifted path for safety improvement, and few studies were conducted for progress management, such as collection and analysis of work results. In addition, the authors revealed that several studies use the combination of existing technologies with new modeling technologies such as BIM (Building Information Modeling). It was also clarified that the technology applied to the monitoring is not even one, but a combination of multiple technologies to achieve each objective. Furthermore, even in the case of monitoring construction equipment, the authors found that workers, construction materials, and even the activity itself are also monitored as well as construction equipment.

Keywords: construction equipment, crane, project management, process monitoring, BIM - building information modeling

\section{INTRODUCTION}

A construction project involves a variety of stakeholders, including the client, the architect, the general contractor, sub-contractors, material suppliers, equipment manufacturers, and so on. The organizational body where they form for each project to carry out construction activities is temporary, so there is a high degree of uncertainty in the environment surrounding the construction work. If the site manager does not monitor changing circumstances adequately, the construction project will much likely run out of the schedule and the budget. Therefore, in managing a 
construction project, progress monitoring is an important matter that provides the basis for the appropriate management and decision-making. It is also essential for improving work safety.

However, the methods of progress monitoring commonly used in construction sites are inaccurate and time-consuming in the data collection and analysis stage. It is also labor-intensive because they rely on large-scale manual operations. The defect of the method has been identified as one of the major problems causing project delays and cost overruns.

Traditional management methods have the following problems.

- Low frequency of Monitoring

- Inefficiency of reporting methods

- Low quality of manually collected data

But in recent years, a variety of emerging automated data collection, analysis, and visualization techniques have been applied to establish methods for digitized, real-time progress monitoring, and there are various papers that address these methodologies and comprehensive reviews.

In this paper, the authors deal with progress monitoring in project management and conduct a review of various studies about how to apply the monitoring of construction equipment to progress monitoring. The aim of this paper is to identify trends in research on "Monitoring construction equipment" and find out what issues need to be studied in the future. Note that "Monitoring construction equipment" means both "monitoring of the construction equipment" and "the construction equipment which is monitoring some other objects" on a construction site.

Then, the authors classified those papers by technology, purpose, and subject matter. It was revealed that most of the studies were focused on digitalization and review of the lifted path for safety improvement. Only a few studies were conducted for progress management, such as collection and analysis of work results. In addition, the authors revealed that several studies use the combination of existing technologies with new modeling technologies such as BIM (Building Information Modeling).

It was also clarified that the technology applied to the monitoring is not even one, but a combination of multiple technologies to achieve each objective. Furthermore, even in the case of monitoring construction equipment, the authors found that workers, construction materials, and even the activity itself are also monitored aw well as construction equipment.

The only results grasped in this paper were technical research. At the actual construction site, consideration must be given to the general contractor responsible for the safe use of the crane. It should also be remembered that the number of crane operators will decrease in the future. The author would like to note these issues in this paper.

\section{PAST STUDIES}

Above mentioned issues can be found in several past papers. Until now, progress management has relied too much on human experience and intuition.
As a result, a lot of time has been spent acquiring and analyzing the necessary data. Also, because it is done subjectively, data errors frequently occur (Davidson and Skibniewski, 1995; Cheng and Chen, 2002). Traditional management methods have the following problems.

\section{- Low frequency of Monitoring}

In most construction sites, monitoring of progress is not conducted in real-time, but rather daily, or less frequently. Manual data collection often does not allow for corrective interventions because construction workers complete the activities before the feedback information reaches the decisionmakers (Sacks et al., 2005; Reboij et al., 2010; Isaac \& Navon, 2014).

\section{- Inefficiency of reporting methods}

When reporting on the construction progress, the site manager must have reporting methods that express and convey various information about the construction site clearly and intelligibly to others (Koo and Fischer, 2000). GolparvarFard and Lee, (2009) recognized the inefficiencies of the existing progress reporting methods in presenting and visualizing multivariable site information and developed a system to understand the difference between time-lapsed photographs taken during the construction process and $4 \mathrm{D}$ simulation models created in the planning stage of pre-construction.

\section{- Low quality of manually collected data}

The collected data must be of high quality because it is the basis for decision making by the site manager and coordination among stakeholders. This requires accurate information on the completion of construction in progress, the site environment such as weather and soil, and the quality of materials. However, manual collection of progress information is based on the manager's experience and so there is a risk that it could be subjective (Yoon et al., 2006).

To overcome these problems, there is a need to establish a high quality and rapid method of collecting data and a digital format for tracking and evaluating project-related entities (Kiziltas and Akinci, 2005). Also, it is a necessary to develop a system for monitoring the construction status and modifying the construction plan precisely along the overall construction progress.

In recent years, many researchers have applied sensor-based techniques to construction sites for monitoring construction project-related entities. For example, they are GPS (Global Positioning System), UWB (Ultra-Wide Band), and RFID (Radio Frequency Identifier). Additionally, there are also attempts to analyze image data from construction sites using big data (Han and Golparvar-Fard, 2017), artificial intelligence (Niu et al., 2019), and computer vision technology. Several articles provide a comprehensive review of their technologies (Omar and Nehdi, 2016; Edirisinghe, 2019).

In this context, Haas (2006) mentioned the need to monitor the movement of construction equipment and machinery to 
avoid loss and to improve productivity. The research on the monitoring of construction equipment used in civil engineering work has been done for a longer time compared to construction work. However, not only in civil engineering work but also in building construction work, the efficient use of construction equipment is key to ensuring the construction process as planned. For example, whether the lifting plan and management of cranes is properly carried out has a great impact on the construction schedule, cost-effectiveness, and safety. In the past, monitoring of cranes has been conducted for safety and maintenance purposes. Beyond such a purpose, monitoring the utilization rate of construction equipment could help identifying machines that are not being used efficiently. Machine procurement and machine placement plans can be properly modified with this analysis.

Sacks et al. (2005) made the first attempt in the construction industry to utilize safety devices attached to tower cranes to manage the progress of a construction project. Since the publication of this study, the idea of assisting construction project management by monitoring construction equipment has been spreading among several researchers. However, to the best of the authors' knowledge, there are no articles that have conducted an extensive review of research aimed at progress monitoring.

\section{RESEARCH METHODOLOGY}

The acquisition of the publications was in two stages: comprehensive literature search and literature filtering.

In comprehensive literature search, the authors utilized Google Scholar by Google and ScienceDirect by Elsevier to find related publications and searched for relevant articles using the keyword search. The authors added words or phrases related to construction equipment (e.g., "construction equipment," "mobile cranes," "tower cranes") after "construction progress monitoring by," "AND” for a search.

When searching for articles, the authors did not specify the date of publication of the articles. Therefore, the authors included all the articles published by October 2020 that were accessible on the website. It may not be appropriate to rely on the selection criteria of Google Scholar and ScienceDirect because there is no perfect database, but it is most open to access. For each search attempt, the titles of the publications were manually checked and determined whether they were relevant to the research topic. Total 127 related papers were extracted.

In literature filtering, the authors read the selected literature closely and determined whether it is suitable for this literature review. Papers that described construction equipment but only described support systems during crane selection or papers that described only the summary of the other literature were also discarded.

Overall, 67 relevant publications were obtained by selection and supplement. These articles are from Automation in Construction, Journal of Computing in Civil Engineering, Advanced Engineering Informatics, Construction Management and Economics, Journal of Construction Engineering and

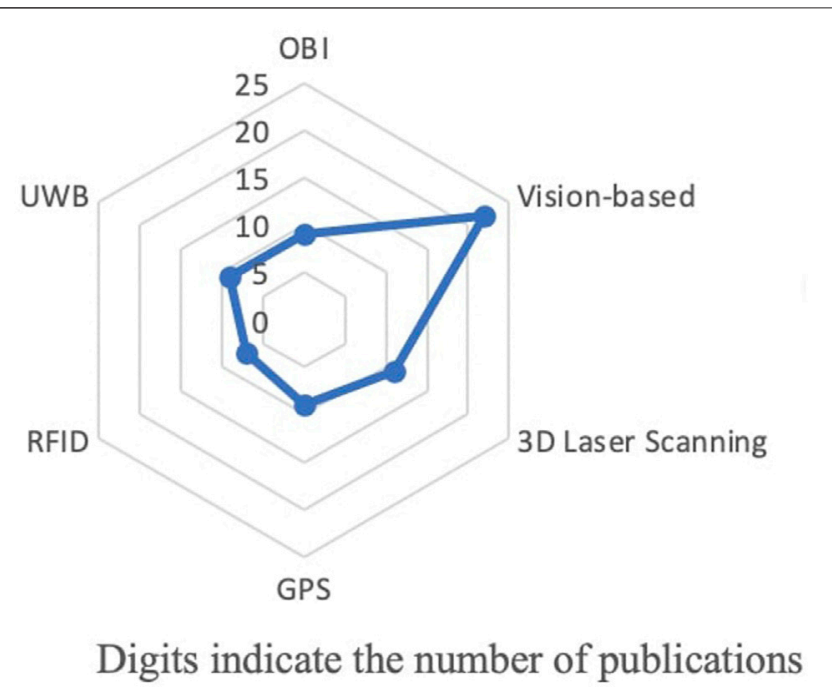

FIGURE 1 | The distribution of technology for monitoring construction equipment.

Management, Safety Science, Advances in Mechanical Engineering, Journal of Information Technology in Construction (ITcon), Automation and Robot Applications, Autonomous Robots, Computer-Aided Civil and Infrastructure Engineering, Journal of Management in Engineering, Journal of Aerospace Engineering, Journal of Civil Engineering and Management, Journal of the Korea Institute of Building Construction, and Management, Procurement and Law.

The total of 59 journal papers and eight conference proceedings papers remained. This result is based on the authors' subjectivity. However, since the purpose of this paper is to know the major trends in research, quantitative criteria are not necessary.

\section{RESULTS}

\section{Technology for Monitoring}

During the investigation, the authors found that either data technologies embedded in the equipment, external to the equipment, or both were used to monitor.

While the data collection technology embedded in the construction equipment is only OBI (On-Board Instrumentation), the data collection technologies external to the equipment used were geospatial tools and imaging technologies. Geospatial tools allow site managers to track the location of an object. These include radio frequency identification, ultra-wide band tags, and global positioning systems.

Also, research on progress monitoring using imaging technologies has been rapidly generated in the research area these years. These include vision-based technologies and 3D laser scanning. Although it can be subdivided into smaller categories, the authors will describe these two technologies in this paper. Most recent research has been focusing on using 
digital images for progress analysis to generate $3 \mathrm{D}$ information about various objects on site.

The distribution of technology for monitoring construction equipment is shown as Figure 1. The most widely used technique is vision-based technologies, with which 22 studies are conducted. 3D laser scanning ranked second (11 times), followed by OBI, GPS, and UWB (nine times). The least used technologies are RFID, with seven papers. More information on each technology is further described in the following sub-sections.

\section{OBI (On-Board Instrumentation)}

OBI (On-Board Instrumentation) is an electronic device embedded in construction machinery and composed of different types of sensors such as inertial sensors, pressure sensors. It is originally used to collect data to prevent equipment failure or to detect anomalies for the purpose of improving safety (Kannan and Vorster, 2000).

The crane's OBI includes an encoder sensor and a load moment indicator. Encoder sensors exist between the crane body and truck base. Or they exist between the boom and the crane boom. They can detect its rotation angle (Fang., 2018). Also, LMI (Load Moment Indicator) can calculate the overturning moment (load multiplied by the radius) on the crane and show it on the display (Fang et al., 2016). OBI and LMI are basic and well-known technology that has been with us for years. It comes equipped with heavy cranes from many crane manufacturers today and is commercialized as an overload prevention system. This system displays to the operator the crane's rated capacity and the percentage of the moment caused by the lifted object and emits a warning sound when the moment exceeds a set threshold. Some operators released the safety device and steered the crane, which could cause an accident. In recent years, the safety device cannot be released.

Moreover, the data obtained by OBI can be extended to information about production activities beyond the contribution of the hardware aspect of the equipment and of assisting in its operation (Kannan and Vorster, 2000). Sacks et al. (2003; 2005) experimented with Potain's “Dialog Visu” control system, which could record the weight and position of a hook in real-time. Although this system was originally developed to improve safety, Sacks et al. $(2003$; 2005) demonstrated that it could automatically record the cycle time of lift activity. Ahn et al. (2015) examined the feasibility of measuring the operational efficiency of equipment using low-cost accelerometers. Akhavian and Behzadan, (2015) trained supervised machine learning classifiers by extracting certain important features from the collected data using accelerometer and gyroscope sensors for detecting and classifying key activities performed in the field by various equipment and human crew. In addition to the raw data from the crane sensors. Ruikar and Amor (2019) monitored the masonry work progress by attaching RFID tags to the material. They calculate the work completion rate by combining the total weight of the suspended parts obtained from the crane sensors and the pallet ID data collected from the RFID tags.

OBI is a significant cost advantage because no additional sensors are needed. In recent years, construction equipment has been equipped with OBI as standard, so no additional cost is needed. However, there are several disadvantages to using OBI for progress monitoring. Ren and $\mathrm{Wu}$ (2015) used the boom head on a mobile crane and existing sensors (i.e., sensors for boom length, boom rotation angle, and elevation angle) to collect obstacle information. However, due to cable stretch and winch spooling, the encoder-based measurement of the cable length is an approximation, and so information accuracy is low (Lytle et al., 2004). Also, the data collected by OBI is not meaningful data for progress monitoring by themselves (Kannan and Vorster, 2000). As the experiments by Ruikar and Amor (2019), it must be combined with information about the state of the materials and the surrounding environment of the site to be an effective technique for progress monitoring. As far as safety is concerned, it is difficult to prevent the swaying of loads and collisions with other cranes and building structures. It is also a disadvantage that there are no sensors other than OBI.

\section{Vision-Based Technologies}

The monitoring activities using vision-based technologies conducted in the reviewed papers were divided into two stages.

The first stage of monitoring is the way of observing the situation in the field with a video camera. Many researchers have been studying video camera observation methods in the field with the aim of improving equipment operators' visibility. For instance, Shapira et al. (2008) designed the live video system on a tower crane to improve the visibility of the operator during the lifting operation. Putnik et al. (2015) proposed a way to provide a crane operator with different views through the cameras mounted around the crane and for the object being handled by the crane. Chen et al. (2017) attached a wide-angle camera to the crane boom to track dynamic obstacles in the crane's workspace. Besides, with the evolution of UAS (Unmanned Aerial System) in recent years, several studies have been conducted to adapt it to progress monitoring. Roberts et al. (2017) focused on how to track the location of a crane by imaging from multiple flying cameras.

The second stage of monitoring is the way of extracting and analyzing the information obtained from images and videos, called computer vision (Brilakis et al., 2011).

Computer vision is a technology that processes raw image information. It extracts the necessary image information, and it is used in various industries. It is allowed for site managers and workers to provide a wealth of information about the construction site by processing a large amount of image data about construction equipment and site environment, using computer vision technology. In other words, this technique can address the limitations of manual approaches to progress monitoring (Seo et al., 2015).

In recent years, researchers have conducted several studies to extract worker and equipment activity, productivity, and construction progress statistics through computer vision-based processing algorithms. Yang et al. (2015) noted that "a foreseeable future is that construction progress can be analyzed, and project schedule can be revised automatically through observation from the visual sensors." 
Ibrahim et al. (2009) presented a method for assessing the completeness of the structure by automatically interpreting images of the construction site. Gong et al. (2011) aimed to investigate the possibility of a new visual learning approach in classifying slight activity categories in various construction video segments. Kim et al. (2013) made inferences about construction progress by automatically updating the $4 \mathrm{D}$ model through an image processing approach. Tajeen and Zhu (2014) proposed a construction site image dataset to enable a computer-visioned method for automatically recognizing equipment on a construction site. Bügler et al. (2014) proposed a method for monitoring the progress of earthwork processes by computer vision. Han and Golparvar-Fard (2017) discussed the potential of big visual data used in conjunction with BIM to analyze construction performance. Also, they introduced model-driven visual analytics, which consists of computer vision and BIM to solve the lack of communication between stakeholders and management issues in the construction projects.

There are various benefits and various ways to adapt visionbased technologies to the construction site as mentioned so far. However, when a fixed-point camera is mounted on some structure to observe the site, there will be blind spots as the construction progresses. Besides, when the camera is mounted on a dynamic object such as a crane, the distance to the object changes (Eickeler and Jahr, 2017). It is a difficult problem to extract progress monitoring information from the image data by processing algorithms.

\section{D Laser Scanning}

When operating construction equipment on a construction site, real-time information about the construction site environment is needed to prevent collisions with dynamic obstacles. Modeling the current construction site conditions and dynamics of the crane workspace is very important (Wang and Cho, 2015).

Ideally, the state of the site should be updated in real-time to capture small changes at any given moment. However, due to technical constraints, updating $3 \mathrm{D}$ geometry in real-time is difficult and costly even if it is possible (Fang et al., 2016). Graphical visualization is difficult in unstructured workplaces, such as construction sites, because of the unpredictability and rapid changes in work practices (Wang and Cho, 2015).

Laser-scanned point clouds can be used to understand the current state of the surrounding objects, including their shapes and colors, and are updated with a hybrid visualization approach that utilizes computer vision efficient data collection, computation, and comprehensive 3D geometric information contained in the point cloud (Chen et al., 2017). Cheng and Teizer (2014) identified blind zones that limit the crane operator's visibility by measuring the condition and shape of the construction site through laser scanning. The framework proposed by Teizer and Cheng (2015) used commercially available wireless (RF) and GPS sensors to record the location of resources in real-time and used a laser scanner (once, at the time of the experiment) to capture the $3 \mathrm{D}$ environment as it was constructed. Fang et al. (2018) used point clouds collected by the laser scanner technique when modeling and updating the site conditions.
Thus, laser scanning technology has been used to collect static site environment information. It is often used in combination with other location-based technologies such as GPS and RFID. However, it has several limitations, because manual scanning is less accurate and timeconsuming (Kim et al., 2011). A focus of future research will be to increase the speed of surface models by using more powerful computers and improving the quality of surface models (Wang and Cho, 2015).

\section{GPS (Global Positioning System)}

GPS (Global Positioning System) is widely used in various industrial sectors due to its ubiquity, high accuracy, and low cost. Since the early 2000s, it has also been used in the construction industry to prevent theft of civil engineering equipment.

Lee et al. (2002) investigated the possibility of improving crane operations by using a GPS. Oloufa et al. (2003) developed a vehicle tracking system using GPS technology to prevent collisions of multiple construction equipment during remote operation using video cameras. Navon and Shpatnisky (2005) developed an automated data collection model using GPS technology to generate the information needed for efficient monitoring of road construction. Abderrahim et al. (2005) carried out the monitoring with small location-based communication instruments attached to a safety helmet, which is required for all workers, to ensure that workers do not suffer from accidents related to falling from a high place or collision with dangerous objects.

GPS has also been applied in the construction industry for material location tracking (Caldas et al., 2006; Song et al., 2006), resource management (Gong and Caldas 2008), and safety management (Teizer et al., 2007), as well as for safety and productivity purposes. In a recent study, Alshibani and Moselhi (2016) proposed a system to collect samples of GPS data in real-time. The data captured by the GPS receiver will be utilized to estimate the cycle time of the equipment.

When obtaining object location information, GPS has the advantage of being able to obtain $x_{-}^{-}, y^{-}$, and $z$-coordinates with only one GPS unit, which can be easily applied in a wide external work environment (Yun and Lee, 2010). However, compared to the use of GPS in open areas such as civil engineering sites, the poor positioning performance of GPS in dense urban construction sites causes the data accuracy and reliability to be very low. This also occurs when used in indoor environments (Abderrahim et al., 2005). Therefore, the authors need to think about where to use GPS in order to apply it effectively for progress monitoring purposes.

\section{RFID (Radio Frequency Identifier)}

RFID (Radio Frequency Identifier) identifies a specific target through radio signals. Depending on battery usage, RFID systems can be classified as active, semi-passive, or passive. An active RFID system can continuously update information in real- time by transmitting information wirelessly to the tags (Ergen et al., 2007; Grau et al., 2009). On the other hand, a 
passive RFID system is ideal for indoor construction applications because of its various advantages in terms of cost, lifetime, and size (Vogt and Teizer, 2007).

Caron et al. (2006) listed the following three potential impacts of RFID in the construction industry. 1) Improving real-time project management and control through analysis of work productivity by tracking materials, 2) Saving time and costs, and 3) Possibility of extending the functionality to safety applications.

Most of the articles on RFID utilized it for material tracking purposes. Yun and Lee (2010) developed and utilized a Zigbeebased wireless recognition tag device. When a worker finished preparing for the lift, the manager pressed a button on the radio-recognition tag, and the RFID information of the component was automatically signaled and stored on a server that was a long-distance away. Cho et al. (2011) developed a material management system that utilizes RFID and USN (Ubiquitous Sensor Network) to obtain information on the movement of materials. Li Y. et al. (2013) developed a real-time monitoring system that integrates GPS and RFID. This system is intended to detect and warn workers of their entry into a predetermined risk zone by acquiring the location of both the site crew and the crane.

Also, RFID can store additional data, such as historical information and technical specifications, in addition to identification data. Integrating with various sensors allows the data collected by those sensors to be stored in RFID tags (Taneja et al., 2011). On the other hand, RFID has a major disadvantage that must be overcome. When used with metallic materials, RFID's error rate increases (Lee et al., 2006).

\section{UWB (Ultra-Wide Band)}

UWB (Ultra-Wide Band) means an ultra-wideband wireless system. This is a wireless communication technology that uses a wide frequency band to enable high-speed communication over short distances. It is usually used in communications for short distances. Because the radio waves in each frequency band are weak, the communication is fast and stable. The possibility of interference with other wireless devices is low. Thus, the accuracy of position detection is very high, with an error margin of a few centimeters.

In the selected papers, UWB was used to track the location of various dynamic objects. Zhang et al. (2009b) collected raw data using the UWB system software showing the tag's name, date, time, and the $\mathrm{x}-, \mathrm{y}-, \mathrm{z}$ - coordinates. Zhang et al. (2012) studied how to estimate the pose of a crane boom by data collected using UWB and processed it into information that can be used for collision avoidance and path replanning. Cheng and Teizer (2013) captured the activities of a mobile crane by multiple UWB tags. They attached four UWB tags to the outriggers, one to the structural frame of the crane cabin, and another to the crane hook to calculate the orientation of the crane boom. In determining the number of tags to be placed on the monitored object, it is necessary to take into account the degree of freedom of the monitored object (Zhang et al., 2009b). Shahi et al. (2013) employed the UWB positioning system as part of an innovative data collection system for capturing job data on construction projects. Workers and inspectors could track specific activities that take place at the location of the tag by temporarily placing a tag on the installed material. Teizer and Cheng (2015) developed a framework that incorporates a UWB to allow equipment operators to accurately determine the location of equipment and assess the possibility of equipment collisions in real-time.

In addition to the above mentioned several advantages, UWB has the advantage that it does not need to be integrated with other technologies to provide accurate $3 \mathrm{D}$ position estimation (Hwang, 2012). On the other hand, UWB's main limitation at this point is a necessary measurement infrastructure (Teizer et al., 2007). As with RFID, obstructions and metal interference in the work environment have a significant negative impact on the accuracy of UWB positioning (Li et al., 2016).

\section{Integration of Visualization With Monitoring}

Integration of the geometrical representation of a building with other types of data, such as time and cost, has been a topic for many research and development efforts (Hammad, 2007).

To improve safety during crane operation, the simulation of cranes in a virtual space (Kang and Miranda, 2006; Zhang et al., 2009a), visualization (Giretti et al., 2009; Kang et al., 2009), the definition of safe areas (Ren and Wu, 2015), and others have been developed.

Visualization and simulation will allow site workers and site managers to understand the situation and work schedule at the site from their perspective. This makes communication smoother and more efficient, which reduces the potential for misunderstandings between the parties involved. Also, it greatly improves the accuracy of the schedule (Kang and Miranda, 2006).

BIM and VR are integrated with the monitoring technologies described before. The integration of visualization with monitoring is described in the following sub-sections.

\section{BIM (Building Information Modeling)}

Recent developments in the field of BIM have enabled vast amounts of information to be stored in a computer-interpretable format (Ibrahim et al., 2009). In the construction phase, BIM is expected to provide essential information for analysis and monitoring of the process, such as construction progress and tracking of construction resources (Fang et al., 2016).

With regard to tracking construction resources, it is necessary to establish an automated material resource tracking system in order to avoid project delays, and to reduce waste. The spending of material resources can effectively serve as an indirect measure of a project's progress (Rebolj et al., 2008).

A variety of research has been conducted to improve safety in the operation of construction equipment. The research is based on the technologies such as the automatic generation of crane lifting paths, provision of $3 \mathrm{D}$ information to operators, warning to the workers of hazardous areas, and identification of hazards through simulation. The system developed by Lee et al. (2009) collects and displays the location of the lifted object in real-time on the BIM model. The lifted route is generated from the BIM database when the worker acquires a material ID. Lee et al. (2012) 
developed a system that collects location on a BIM model of a lifted object in real-time and displays the $3 \mathrm{D}$ building on a monitor in the cabin of a tower crane or the machine control room. Li H. et al. (2013) developed a system that captures worker and crane-positioning information and integrates $3 \mathrm{D}$ positional data into a BIM environment in order to prevent workers from entering hazardous areas. Zhang et al. (2015) performed two 4D simulations in BIM and identified potential struck-by and worker hazards. By comparing the two results, they could determine the level of safety performance expected at a construction site. Liang et al. (2018) presented a real-time construction site layout and equipment monitoring system using BIM.

When it comes to construction progress monitoring, it is much more efficient to share the progress by visualizing the difference between as-planned model and as-built status in BIM than to compare images and Gantt charts that show the current situation (Han and Golparvar-Fard, 2017). Li et al. (2018) used a BIM model captured in a web-based operational platform to visualize the progress of precast construction in real-time, displaying the status of the precast during fabrication, transportation, arrival on-site, and erection with color-coding. By visualizing the progress of domestic construction and the progress in the field in real-time, it is possible to check and understand the delays in precast production and delivery. Such progress visualization allows for more efficient communication and coordination between the management team and field workers than in the past (Fang et al., 2016).

\section{VR (Virtual Reality)}

Many researchers are attempting to combine VR (Virtual Reality) technology with existing sensing technologies for construction management in the pre-construction stage and construction stage.

In the pre-construction stage, it is necessary to identify and eliminate problems and risks early, before the actual construction begins. The main factors that cause construction accidents include lack of site layout, multi-interface, safety screens and scaffolding, multi-plant, construction operations, and safety training, etc. Kang et al. (2009) presented a study to achieve $3 \mathrm{D}$ simulation and animation of the construction process. Guo et al. (2013) proposed a conceptual framework for applying VR technology to construction safety management. However, VR models used in planning and other applications are based on simulated or pre-recorded data, and so far the application of VR at the construction work level has not been very common.

One of the significant challenges of leveraging VR in the construction phase is the integration of captured data in realtime (Cheng and Teizer, 2013). Also, accurately tracking the 3D position of dynamic objects and recognizing their orientation is very important for real-time VR applications. The methods for tracking dynamic objects include tracking the position of the crane using a UWB system (Zhang and Hammad, 2012; Cheng and Teizer, 2013). There are also methods of collecting obstacle information using the boom head on a mobile crane and existing sensors (i.e., sensors for boom length, boom rotation angle, and elevation angle) (Ren and $\mathrm{Wu}, 2015)$, and collecting site environment information through point clouds generated from images recorded by crane-based cameras (Eickeler and Jahr, 2017).

The research field of integrating the sensing technology used in the above-mentioned methods with VR technology is an area of growing interest for several researchers in recent years. For instance, Kan et al. (2018) applied CPS (Cyber-Physical System) to mobile crane planning and operation to enhance bi-directional coordination between physical components of the construction site and virtual representations to address the dynamic environment of a construction project. However, there are several difficulties in estimating accurately the movement of mobile cranes and ensuring the reliability of the collected data. To address these difficult issues, significant investment and empirical data collection from practical case studies are required.

Besides, project stakeholders (equipment operators, field workers, and safety management commands) can make more informed decisions in a shorter time and at a lower cost by monitoring video data processed live in the VR world (Kang and Miranda, 2006; Cheng \& Teizer, 2013). An experiment by Rebolj et al. (2008) reported that project participants residing in a virtual workspace established cross-functional/organizational communication and avoided the traditional chain of command.

\section{Barriers of Visualization}

On the other hand, there are several barriers to implement VR technology.

First, VR technology requires considerable early-stage investment for software and hardware. Investment before the guaranteed benefits can be a barrier to some stakeholders.

Secondly, it can be difficult to sense data from VR technology because those data are particularly vulnerable to the interference of other signals.

Lastly, there is still a delay in real-time visualization of the data, and therefore there is a need to minimize the delay and ensure timely control feedback (Kan et al., 2018). Overcoming these barriers will require more research in the future.

\section{DISCUSSION}

\section{Objectives of Monitoring}

The authors divided the objectives of monitoring in the past research into four categories. The objectives of each study, the technologies applied, and each objective of monitoring are shown in Table 1. The brackets next to the technology represent the number of references.

\section{Improvement of Safety in Equipment Operations}

It is shown that the general objective of monitoring is improvement of safety.

Errors in the operation of equipment at construction sites are a major cause of construction accidents such as falls, collisions with structures, and collisions with other cranes. This is mainly due to the presence of various dynamic obstacles on the construction site, in addition to operator visibility issues such as blind spots (Kim et al., 2006). To operate construction equipment safely and effectively, the dynamic spatial information on a cluttered 
TABLE 1 | A list of objectives and targets of the technology.

\begin{tabular}{|c|c|c|c|c|c|}
\hline \multirow{2}{*}{$\frac{\text { Target objects }}{\text { Objective }}$} & \multirow[t]{2}{*}{ Static } & \multirow{2}{*}{$\frac{\text { Semi-static }}{\text { Site environment }}$} & \multicolumn{3}{|c|}{ Dynamic } \\
\hline & & & Construction equipment & Material & Worker \\
\hline Improvement of safety & $\mathrm{OBI}(1) \mathrm{LS}(1)$ & Vision(1) LS(2) & OBI(2) Vision(4) LS(2) GPS(1) UWB(6) & $\mathrm{OBI}(1) \mathrm{B}(2) \mathrm{LS}(1) \mathrm{RFID}(1)$ & Vision(2) GPS(2) RFID(1) UWB(4) \\
\hline Improvement of productivity & - & - & OBI(2) Vision(3) GPS(3) RFID(1) & Vision(1) RFID(1) & RFID(1) \\
\hline Automation of operation & - & Vision(1) & $\mathrm{OBI}(1)$ Vision(1) LS(1) & Vision(1) LS(2) D(1) RFID(1) & Vision(1) LS(1) \\
\hline Progress monitoring & $\operatorname{LS}(1)$ & Vision(4) & OBI(2) GPS(1) & $\mathrm{OBI}(1) \mathrm{RFID}(2) \mathrm{UWB}(1)$ & - \\
\hline
\end{tabular}

construction site needs to be collected quickly. Several field safety devices have been developed that, if properly utilized, could reduce the number of crane-related injuries and fatalities, but the extent and effect of their utilization are unsatisfactory ( $\mathrm{Li}$ and Liu, 2012). Therefore, in addition to monitoring the construction equipment, it is necessary to monitor the site environment, workers, and other cranes.

The technical development is important, but the discussion about responsibility of general contractors is not enough. For example, who covers responsibility for crane operator's mistake? If the responsibility of the general contractor does not change, even cranes equipped with new technologies will not be used very often.

Improvement of Productivity in Equipment Operations Construction equipment productivity analysis is the most essential construction equipment management practice that has the potential to improve the productivity of construction projects (Gurmu and Aibinu, 2017). The data obtained by tracking construction equipment can be useful for managers to understand and monitor site performance and conditions, as well as potentially improve the cost efficiency, operability, and safety of cranes (Kim and Chi, 2017). Most of the studies monitored only construction equipment and analyzed the data obtained.

Such techniques may certainly be useful in finding delays in construction. However, the data presented in these studies are already available to site managers. It is necessary to clearly indicate that there are many breaks in the operating hours of the crane and increase the operating rate of the crane operators. It should be noted that the number of excellent crane operators will decrease in the future. It is important to be able to operate the crane even by unskilled workers.

\section{Automating Equipment Operations}

To automate the operation of construction equipment, sensors are introduced to enable any reaction to dynamic changes within the worksite without human intervention (Lytle et al., 2004). Therefore, it is necessary to monitor both the site environment and dynamic objects.

Currently, unmanned cranes are not allowed due to legal restrictions. Unmanned cranes will not be preferred unless the general contractor's responsibilities are reduced. However, unmanned cranes may be required in combination with construction robots at construction sites in harsh conditions that are inaccessible to workers, for example, inside of nuclear power plants, disaster recovery works, and construction sites in deserts and mountains.

\section{Progress Monitoring and Decision-Making Support}

Besides the research objectives closed to the machine itself, there are several studies aimed at improving the quality of project management and decision support.

To improve the quality of project management and support decision-making, including improving productivity other than machinery, it is necessary to monitor the situation at construction sites as well as construction equipment. In recent years, many researchers have used BIM and VR technologies to visualize and simulate the construction phase. If there is a lack of detailed information about the activities where the crane is used and about the environment around the crane, the results of the visualization and simulation will be inaccurate (Li H. et al., 2013). Therefore, most studies used multiple technologies to collect information. They applied various techniques and algorithms to analyze that information.

These techniques are useful for instructing construction workers about the work of the day. The evaluation from the workers is also high. However, it should be noted that visualization techniques are not so much needed in construction planning. Unless it is a building with a very large building area, construction planning is possible without such technology.

\section{Future Development Issues}

In this research, the authors reviewed many papers on cranes. The development of various technologies is categorized, but there is a lack of discussion about changes in crane users and changes in organizational responsibilities including general contractors.

If the crane can be operated by non-skilled operators, the shortage of future operators will be alleviated. If another kind of worker operates the crane, the waiting time will be shortened and the work efficiency will be improved.

The general contractor's responsibility for safety remains unchanged. So, new technology should not be aimed at reducing the number of site managers in general contractor, but rather at reducing the burden on site managers.

\section{CONCLUSIONS}

This research aimed to explore how construction equipment, such as cranes, can support project management. Cranes can monitor other objects and cranes can also be monitored as well as 
their original work. Therefore, the authors applied a two-stage literature review to search for state-of-the-art literature. As a result, the authors found the following four points.

1) Most of the studies were focused on digitalization and review of the lifted path for safety improvement. However, few studies have focused on progress monitoring and decisionmaking support. There is room for further research and development in this field.

2) The monitored object is not limited to construction equipment, but also extends to workers, construction materials, and even the activity itself, even in the case of monitoring construction equipment. The research aimed at improving safety requires information about the location of the equipment as well as the surrounding environment when operating the equipment. In such cases, advanced systems using a plurality of the aforementioned techniques have been devised.

3) There are various objects on a construction site. So the appropriate technology to collect and track information is different, depending on the nature of them. For instance, imaging technologies such as computer vision and 3D laser scanning are used to collect and track information on static or semi-static objects such as area topography, structures, and material depots. On the other hand, geospatial tools such as GPS or UWB are used to collect and track information on dynamic objects, e.g., construction equipment, material, and worker.

4) In the case of research aimed at improving machine productivity, progress monitoring, and decision-making support, only the construction equipment or the field

\section{REFERENCES}

Abderrahim, M., Garcia, E., Diez, R., and Balaguer, C. (2005). A Mechatronics Security System for the Construction Site. Automation in Construction 14, 460-466. doi:10.1016/j.autcon.2004.09.007

Ahn, C. R., Lee, S. H., and Peña-Mora, F. (2015). Application of Low-Cost Accelerometers for Measuring the Operational Efficiency of a Construction Equipment Fleet. J. Comput. Civ. Eng. 29, 04014042. doi:10.1061/(asce)cp.19435487.0000337

Akhavian, R., and Behzadan, A. H. (2015). Construction Equipment Activity Recognition for Simulation Input Modeling Using Mobile Sensors and Machine Learning Classifiers. Adv. Eng. Inform. 29, 867-877. doi:10.1016/ j.aei.2015.03.001

Alshibani, A., and Moselhi, O. (2016). Productivity Based Method for Forecasting Cost \& Time of Earthmoving Operations Using Sampling GPS Data. J. Inf. Tech. Construction (Itcon) 21, 39-56. Available at: http://www.itcon.org/2016/3

Azimi, R., Lee, S., AbouRizk, S. M., and Alvanchi, A. (2011). A Framework for an Automated and Integrated Project Monitoring and Control System for Steel Fabrication Projects. Automation in Construction 20, 88-97. doi:10.1016/ j.autcon.2010.07.001

Azuma, R., Baillot, Y., Behringer, R., Feiner, S., Julier, S., and MacIntyre, B. (2001). Recent Advances in Augmented Reality. IEEE Comput. Grap. Appl. 21, 34-47. doi:10.1109/38.963459

Brilakis, I., Park, M.-W., and Jog, G. (2011). Automated Vision Tracking of Project Related Entities. Adv. Eng. Inform. 25, 713-724. doi:10.1016/j.aei.2011.01.003

Bügler, M., Ongunmakin, G., Teizer, J., Vela, P. A., and Borrmann, A. (2014). “A Comprehensive Methodology for Vision-Based Progress and Activity Estimation of Excavation Processes for Productivity Assessment," in Proceeding of the EG-ICE environment is monitored. However, for more effective progress monitoring and decision-making support, site managers need to expand the scope of monitoring, since external factors such as lifting materials, workers, delivery, and weather conditions are also significantly responsible for progress monitoring.

Consequently, research into applying a system that aims to improve safety to progress monitoring, a system that can monitor multiple sites, or a system that fuses collected information is a necessary research field in the future. Meanwhile, the study of Kan et al. (2018) deals with physical components and information flow in virtual space. This is a very interesting area for future research as it allows multiple in-situ data to be reflected in modeling in virtual space Azimi et al., 2011, Azuma et al., 2001, Costin et al., 2012, Irizarry and Costa, 2016, Lu et al., 2007, Naticchia et al., 2013, Ren et al., 2017, Stone et al., 1999, Teizer et al., 2010, Yang et al., 2014.

\section{AUTHOR CONTRIBUTIONS}

YN mainly wrote this paper and TK and SN provided guidance and corrections to complete this review.

\section{ACKNOWLEDGMENTS}

The authors are grateful to Masaaki Wagawa for helpful discussions and advice based on work experience.

Workshop on Intelligent Computing in Engineering, Cardiff, Wales. doi:10.13140/ RG.2.1.4630.2561

Caldas, C. H., Torrent, D. G., and Haas, C. T. (2006). Using Global Positioning System to Improve Materials-Locating Processes on Industrial Projects. J. Constr. Eng. Manage. 132, 741-749. doi:10.1061/(asce)0733-9364(2006)132:7(741)

Caron, F., Razavi, S. N., Song, J., Vanheeghe, P., Duflos, E., Caldas, C., et al. (2006). Locating Sensor Nodes on Construction Projects. Auton. Robot 22, 255-263. doi:10.1007/s10514-006-9720-1

Chen, J., Fang, Y., and Cho, Y. K. (2017). Real-time 3D Crane Workspace Update Using a Hybrid Visualization Approach. J. Comput. Civ. Eng. 31, 04017049. doi:10.1061/(ASCE)CP.1943-5487.0000698

Cheng, M.-Y., and Chen, J.-C. (2002). Integrating Barcode and GIS for Monitoring Construction Progress. Automation in Construction 11, 23-33. doi:10.1016/ S0926-5805(01)00043-7

Cheng, T., and Teizer, J. (2014). Modeling Tower Crane Operator Visibility to Minimize the Risk of Limited Situational Awareness. J. Comput. Civ. Eng. 28, 04014004. doi:10.1061/(ASCE)CP.1943-5487.0000282

Cheng, T., and Teizer, J. (2013). Real-time Resource Location Data Collection and Visualization Technology for Construction Safety and Activity Monitoring Applications. Automation in Construction 34, 3-15. doi:10.1016/ j.autcon.2012.10.017

Cho, C.-Y., Kwon, S., Shin, T.-H., Chin, S., and Kim, Y.-S. (2011). A Development of Next Generation Intelligent Construction Liftcar Toolkit for Vertical Material Movement Management. Automation in Construction 20, 14-27. doi:10.1016/j.autcon.2010.07.008

Costin, A., Pradhananga, N., and Teizer, J. (2012). Leveraging Passive RFID Technology for Construction Resource Field Mobility and Status Monitoring in a High-Rise Renovation Project. Automation in Construction 24, 1-15. doi:10.1016/j.autcon.2012.02.015 
Davidson, I. N., and Skibniewski, M. J. (1995). Simulation of Automated Data Collection in Buildings. J. Comput. Civil Eng. 9, 9-20. doi:10.1061/(asce)08873801(1995)9:1(9)

Edirisinghe, R. (2019). Digital Skin of the Construction Site. Eng. Construction Architectural Manag. 26, 184-223. doi:10.1108/ECAM-04-2017-0066

Eickeler, F., and Jahr, K. (2017). "Prediction and Simulation of Crane Based Camera Configurations for Construction Site Monitoring," in Conference: 29. Forum Bauinformatik, Dresden, September 2017.

Ergen, E., Akinci, B., East, B., and Kirby, J. (2007). Tracking Components and Maintenance History Within a Facility Utilizing Radio Frequency Identification Technology Fication Technology. J. Comput. Civ. Eng. 21, 11-20. doi:10.1061/ (asce)0887-3801(2007)21:1(11)

Fang, Y., Cho, Y. K., and Chen, J. (2016). A Framework for Real-Time Pro-active Safety Assistance for Mobile Crane Lifting Operations. Automation in Construction 72, 367-379. doi:10.1016/j.autcon.2016.08.025

Fang, Y., Cho, Y. K., Durso, F., and Seo, J. (2018). Assessment of Operator's Situation Awareness for Smart Operation of Mobile Cranes. Automation in Construction 85, 65-75. doi:10.1016/j.autcon.2017.10.007

Giretti, A., Carbonari, A., Naticchia, B., and Grassi, M. D. (2009). Design and First Development of an Automated Real-Time Safety Management System for Construction Sites. J. Civil Eng. Manag. 15, 325-336. doi:10.3846/13923730.2009.15.325-336

Golparvar-Fard, M., Peña-Mora, F., Arboleda, C. A., and Lee, S. (2009). Visualization of Construction Progress Monitoring with 4D Simulation Model Overlaid on Time-Lapsed Photographs. J. Comput. Civ. Eng. 23, 391-404. doi:10.1061/(asce)0887-3801(2009)23:6(391)

Gong, J., and Caldas, C. H. (2008). Data Processing for Real-Time Construction Site Spatial Modeling. Automation in Construction 17, 526-535. doi:10.1016/ j.autcon.2007.09.002

Gong, J., Caldas, C. H., and Gordon, C. (2011). Learning and Classifying Actions of Construction Workers and Equipment Using Bag-Of-Video-Feature-Words and Bayesian Network Models. Adv. Eng. Inform. 25, 771-782. doi:10.1016/j.aei.2011.06.002

Grau, D., Caldas, C. H., Haas, C. T., Goodrum, P. M., and Gong, J. (2009). Assessing the Impact of Materials Tracking Technologies on Construction Craft Productivity. Automation in Construction 18, 903-911. doi:10.1016/ j.autcon.2009.04.001

Guo, H. L., Li, H., and Li, V. (2013). VP-based Safety Management in Large-Scale Construction Projects: A Conceptual Framework. Automation in Construction 34, 16-24. doi:10.1016/j.autcon.2012.10.013

Gurmu, A. T., and Aibinu, A. A. (2017). Construction Equipment Management Practices for Improving Labor Productivity in Multistory Building Construction Projects. J. Construction Eng. Manag. 143, 1-13. doi:10.1061/ (ASCE)CO.1943-7862.0001384

Haas, C. (2006). "A Model for Data Fusion in Civil Engineering," in Intelligent Computing in Engineering and Architecture. EG-ICE 2006. Lecture Notes in Computer Science. Editor I. F. C. Smith (Berlin, Heidelberg: Springer) 4200. doi:10.1007/11888598_29

Hammad, A. (2007). "Framework for Lifecycle Status Tracking and Visualization of Constructed Facility Components," in Proceeding of the 7th International Conference on Construction Applications of Virtual Reality, Penn State University, PA, January 2007, 224-232.

Han, K. K., and Golparvar-Fard, M. (2017). Potential of Big Visual Data and Building Information Modeling for Construction Performance Analytics: An Exploratory Study. Automation in Construction 73, 184-198. doi:10.1016/j.autcon.2016.11.004

Hwang, S. (2012). Ultra-wide Band Technology Experiments for Real-Time Prevention of Tower Crane Collisions. Automation in Construction 22, 545-553. doi:10.1016/j.autcon.2011.11.015

Ibrahim, Y. M., Lukins, T. C., Zhang, X., Trucco, E., and Kaka, A. P. (2009). Towards Automated Progress Assessment of Workpackage Components in Construction Projects Using Computer Vision. Adv. Eng. Inform. 23, 93-103. doi:10.1016/j.aei.2008.07.002

Irizarry, J., and Costa, D. B. (2016). Exploratory Study of Potential Applications of Unmanned Aerial Systems for Construction Management Tasks. J. Manage. Eng. 32, 1-10. doi:10.1061/(asce)me.1943-5479.0000422

Isaac, S., and Navon, R. (2014). Can Project Monitoring and Control Be Fully Automated? Construction Manag. Econ. 32, 495-505. doi:10.1080/01446193.2013.795653

Kan, C., Fang, Y., Anumba, C. J., and Messner, J. I. (2018). A Cyber-Physical System (CPS) for Planning and Monitoring Mobile Cranes on Construction Sites. Proc. Inst. Civil Eng. - Manag. Procurement L. 171, 240-250. doi:10.1680/jmapl.17.00042
Kang, S. C., Chi, H. L., and Miranda, E. (2009). Three-dimensional Simulation and Visualization of Crane Assisted Construction Erection Processes. J. Comput. Civ. Eng. 23, 1-10. doi:10.1061/(asce)0887-3801(2009)23:6(363)

Kang, S., and Miranda, E. (2006). Planning and Visualization for Automated Robotic Crane Erection Processes in Construction. Automation in Construction 15, 398-414. doi:10.1016/j.autcon.2005.06.008

Kannan, G., and Vorster, M. (2000). Development of an Experience Database for Truck Loading Operations. J. Constr. Eng. Manage. 126, 201-209. doi:10.1061/ (asce)0733-9364(2000)126:3(201)

Kim, C., Haas, C. T., Liapi, K. A., and Caldas, C. H. (2006). Human-assisted Obstacle Avoidance System Using 3D Workspace Modeling for Construction Equipment Operation. J. Comput. Civ. Eng. 20, 177-186. doi:10.1061/(asce) 0887-3801(2006)20:3(177)

Kim, C., Kim, B., and Kim, H. (2013). 4D CAD Model Updating Using Image Processing-Based Construction Progress Monitoring. Automation in Construction 35, 44-52. doi:10.1016/j.autcon.2013.03.005

Kim, C., Lee, J., Cho, M., and Kim, C. (2011). "Fully Automated Registration of 3D CAD Model with point Cloud from Construction Site," in Proceeding of the 28th International Symposium on Automation and Robotics in Construction, Seoul, Korea, 917-922. doi:10.22260/isarc2011/0169

Kim, J., and Chi, S. (2017). Adaptive Detector and Tracker on Construction Sites Using Functional Integration and Online Learning. J. Comput. Civ. Eng. 31, 1-13. doi:10.1061/(ASCE)CP.1943-5487.0000677

Kiziltas, S., and Akinci, B. (2005). “The Need for Prompt Schedule Update by Utilizing Reality Capture Technologies: A Case Study," in Proceedings of the Construction Research Congress, San Diego, CA, April 2005. doi:10.1061/40754(183)32

Lee, G., Cho, J., Ham, S., Lee, T., Lee, G., Yun, S.-H., et al. (2012). A BIM- and Sensor-Based Tower Crane Navigation System for Blind Lifts. Automation in Construction 26, 1-10. doi:10.1016/j.autcon.2012.05.002

Lee, G., Kim, H.-H., Lee, C.-J., Ham, S.-I., Yun, S.-H., Cho, H., et al. (2009). A LaserTechnology-Based Lifting-Path Tracking System for a Robotic Tower Crane. Automation in Construction 18, 865-874. doi:10.1016/j.autcon.2009.03.011

Lee, J. H., Park, S. J., Oh, S. W., and Kim, Y. S. (2002). A Study on the Work Efficiency Improvement of Tower Crane Operation Using GPS and Machine Vision. J. Architectural Inst. Korea 18, 133-140.

Lee, U.-K., Kang, K.-I., Kim, G.-H., and Cho, H.-H. (2006). Improving Tower Crane Productivity Using Wireless Technology. Computer-aided Civil Eng. 21, 594-604. doi:10.1111/j.1467-8667.2006.00459.x

Li, C. Z., Xue, F., Li, X., Hong, J., and Shen, G. Q. (2018). An Internet of Things-Enabled BIM Platform for On-Site Assembly Services in Prefabricated Construction. Automation in Construction 89, 146-161. doi:10.1016/j.autcon.2018.01.001

Li, H., Chan, G., and Skitmore, M. (2013a). Integrating Real Time Positioning Systems to Improve Blind Lifting and Loading Crane Operations. Construction Manag. Econ. 31, 596-605. doi:10.1080/01446193.2012.756144

Li, H., Chan, G., Wong, J. K. W., and Skitmore, M. (2016). Real-time Locating Systems Applications in Construction. Automation in Construction 63, 37-47. doi:10.1016/j.autcon.2015.12.001

Li, Y., and Liu, C. (2012). Integrating Field Data and 3D Simulation for Tower Crane Activity Monitoring and Alarming. Automation in Construction 27, 111-119. doi:10.1016/j.autcon.2012.05.003

Li, Y., Wang, S., and Li, B. (2013b). Improved Visual Hook Capturing and Tracking for Precision Hoisting of Tower Crane. Adv. Mech. Eng. 5, 426810-426818. doi: $10.1155 / 2013 / 426810$

Liang, C.-J., Kamat, V. R., and Menassa, C. M. (2018). Real-time Construction Site Layout and Equipment Monitoring. Construction Res. Congress 2018, 64-74. doi:10.1061/9780784481264.007

Lu, M., Chen, W., Shen, X., Lam, H.-C., and Liu, J. (2007). Positioning and Tracking Construction Vehicles in Highly Dense Urban Areas and Building Construction Sites. Automation in Construction 16, 647-656. doi:10.1016/ j.autcon.2006.11.001

Lytle, A. M., Saidi, K. S., Bostelman, R. V., Stone, W. C., and Scott, N. A. (2004). Adapting a Teleoperated Device for Autonomous Control Using Three-Dimensional Positioning Sensors: Experiences with the NIST RoboCrane. Automation in Construction 13, 101-118. doi:10.1016/ j.autcon.2003.08.009

Naticchia, B., Vaccarini, M., and Carbonari, A. (2013). A Monitoring System for Real-Time Interference Control on Large Construction Sites. Automation in Construction 29, 148-160. doi:10.1016/j.autcon.2012.09.016 
Navon, R., and Shpatnitsky, Y. (2005). A Model for Automated Monitoring of Road Construction. Construction Manag. Econ. 23, 941-951. doi:10.1080/ 01446190500183917

Niu, Y., Lu, W., Xue, F., Liu, D., Chen, K., Fang, D., et al. (2019). Towards the "third Wave": An SCO-Enabled Occupational Health and Safety Management System for Construction. Saf. Sci. 111, 213-223. doi:10.1016/j.ssci.2018.07.013

Oloufa, A. A., Ikeda, M., and Oda, H. (2003). Situational Awareness of Construction Equipment Using GPS, Wireless and Web Technologies. Automation in Construction 12, 737-748. doi:10.1016/S0926-5805(03)00057-8

Omar, T., and Nehdi, M. L. (2016). Data Acquisition Technologies for Construction Progress Tracking. Automation in Construction 70, 143-155. doi:10.1016/j.autcon.2016.06.016

Putnik, G., Shah, V., Spasojević-Brkić, V., Alves, C., and Castro, H. (2015). “A Proposal for Installation Architecture for Video Cameras and Screens in an Integrated Vision System for crane Cabins," in Proceeding of the 9th International Quality Conference, June 2015 (Serbia: University of Kragujevac), 633-640. Available at: http://www.cqm.rs/2015/cd1/pdf/papers/ focus_2/100.pdf.

Rebolj, D., Babič, N. Č., Magdič, A., Podbreznik, P., and Pšunder, M. (2008). Automated Construction Activity Monitoring System. Adv. Eng. Inform. 22, 493-503. doi:10.1016/j.aei.2008.06.002

Rebolj, D., Babic, N. C., and Podbreznik, P. (2010). “Automated Building Process Monitoring," in Handbook of Research on Building Information Modeling and Construction Informatics: Concepts and Technologies, IGI Global. Editors J. Underwood and U. Isikdag, 190-211. doi:10.4018/978-1-60566-928-1.ch009

Ren, W., and Wu, Z. (2015). Real-time Anticollision System for mobile Cranes During Lift Operations. J. Comput. Civ. Eng. 29, 1-12. doi:10.1061/(ASCE) CP.1943-5487.0000438

Ren, X., Zhu, Z., Germain, C., Belair, R., and Chen, Z. (2017). Automated Monitoring of the Utilization Rate of Onsite Construction Equipment. Comput. Civil Eng. 2017. doi:10.1061/9780784480830.010

Roberts, D., Bretl, T., and Golparvar-Fard, M. (2017). Detecting and Classifying Cranes Using Camera-Equipped UAVs for Monitoring Crane-related Safety Hazards. ASCE Int. Workshop Comput. Civil Eng. 2017. doi:10.1061/ 9780784480847.055

Ruikar, K., and Amor, R. (2019). A Rule-Based Methodology for Automated Progress Monitoring of Construction Activities: A Case for Masonry Work. J. Inf. Tech. Construction (Itcon) 24, 188-208.

Sacks, R., Navon, R., Brodetskaia, I., and Shapira, A. (2005). Feasibility of Automated Monitoring of Lifting Equipment in Support of Project Control. J. Constr. Eng. Manage. 131, 604-614. doi:10.1061/(asce)0733-9364(2005)131:5(604)

Sacks, R., Navon, R., Shapira, A., and Brodetsky, I. (2003). "Monitoring Construction Equipment for Automated Project Performance Control," in 2002 Proceedings of the 19th ISARC, Washington, 161-166. doi:10.22260/ ISARC2002/0025

Seo, J., Han, S., Lee, S., and Kim, H. (2015). Computer Vision Techniques for Construction Safety and Health Monitoring. Adv. Eng. Inform. 29, 239-251. doi:10.1016/j.aei.2015.02.001

Shahi, A., West, J. S., and Haas, C. T. (2013). Onsite 3D Marking for Construction Activity Tracking. Automation in Construction 30, 136-143. doi:10.1016/ j.autcon.2012.11.027

Shapira, A., Rosenfeld, Y., and Mizrahi, I. (2008). Vision System for Tower Cranes. J. Constr. Eng. Manage. 134, 320-332. doi:10.1061/(asce)0733-9364(2008)134: $5(320)$

Song, J., Haas, C. T., and Caldas, C. H. (2006). Tracking the Location of Materials on Construction Job Sites. J. Constr. Eng. Manage. 132, 911-918. doi:10.1061/ (asce)0733-9364(2006)132:9(911)

Stone, W., Reed, K., Chang, P., Pfeffer, L., and Jacoff, A. (1999). NIST Research Toward Construction Site Integration and Automation. J. Aerospace Eng. 12, 50-57. doi:10.1061/(asce)0893-1321(1999)12:2(50)

Tajeen, H., and Zhu, Z. (2014). Image Dataset Development for Measuring Construction Equipment Recognition Performance. Automation in Construction 48, 1-10. doi:10.1016/j.autcon.2014.07.006

Taneja, S., Akinci, B., Garrett, J. H., Soibelman, L., Ergen, E., Pradhan, A., et al. (2011). Sensing and Field Data Capture for Construction and Facility Operations. J. Constr. Eng. Manage. 137, 870-881. doi:10.1061/(ASCE) CO.1943-7862.0000332
Teizer, J., Allread, B. S., and Mantripragada, U. (2010). Automating the Blind Spot Measurement of Construction Equipment. Automation in Construction 19, 491-501. doi:10.1016/j.autcon.2009.12.012

Teizer, J., and Cheng, T. (2015). Proximity Hazard Indicator for Workers-On-Foot Near Miss Interactions with Construction Equipment and Geo-Referenced Hazard Areas. Automation in Construction 60, 58-73. doi:10.1016/ j.autcon.2015.09.003

Teizer, J., Lao, D., and Sofer, M. (2007). "Rapid Automated Monitoring of Construction Site Activities Using Ultra-wideband," in Proceedings of the 24 the International Symposium on Automation \& Robotics in Construction, Kochi, India, September 2007, 23-28. doi:10.22260/isarc2007/0008

Vogt, B., and Teizer, J. (2007). "Sparse Laser Scanning to Improve Off-Shore PipeFitting Productivity," in Proceedings of the Construction Research Congress, Freeport, Bahamas, May 2007.

Wang, C., and Cho, Y. K. (2015). Smart Scanning and Near Real-Time 3D Surface Modeling of Dynamic Construction Equipment from a Point Cloud. Automation in Construction 49, 239-249. doi:10.1016/j.autcon.2014.06.003

Yang, J., Park, M.-W., Vela, P. A., and Golparvar-Fard, M. (2015). Construction Performance Monitoring via Still Images, Time-Lapse Photos, and Video Streams: Now, Tomorrow, and the Future. Adv. Eng. Inform. 29, 211-224. doi:10.1016/j.aei.2015.01.011

Yang, J., Vela, P. A., Teizer, J., and Shi, Z. K. (2014). Vision-Based Tower Crane Tracking for Understanding Construction Activity. J. Comput. Civ. Eng. 28, 1-34. doi:10.1061/(ASCE)CP.1943-5487.0000242

Yoon, S.-W., Chin, S., Kim, Y.-S., and Kwon, S.-W. (2006). “An Application Model of RFID Technology on Progress Measurement and Management of Construction Works," in Proceedings of the International Symposium on Automation and Robotics in Construction (IAARC),Proceedings of the 23rd International Symposium on Automation and Robotics in Construction, Tokyo, Japan, 779-783. doi:10.22260/ISARC2006/0144

Yun, S.-H., and Lee, G. (2010). Development of a Real-Time Lifting-Path Tracking System of a Tower-crane for Steel Members Based on an Integrated Wireless RF Modem and GPS System. J. Korean Inst. Building Construction 10, 65-70. doi:10.5345/jkic.2010.10.3.065

Zhang, C., Hammad, A., and AlBahnassi, H. (2009b). "Path Re-Planning of Cranes Using Real-Time Location System," in 2009 Proceedings of the 26th ISARC, Austin, USA, 412-419. doi:10.22260/ISARC2009/0059

Zhang, C., Hammad, A., and Bahnassi, H. (2009a). Collaborative Multi-Agent Systems for Construction Equipment Based on Real-Time Field Data Capturing. J. Inf. Tech. Construction (Itcon) 14, 204-228.

Zhang, C., and Hammad, A. (2012). Multiagent Approach for Real-Time Collision Avoidance and Path Replanning for Cranes. J. Comput. Civ. Eng. 26, 782-794. doi:10.1061/(ASCE)CP.1943-5487.0000181

Zhang, C., Hammad, A., and Rodriguez, S. (2012). Crane Pose Estimation Using UWB Real-Time Location System. J. Comput. Civ. Eng. 26, 625-637. doi:10.1061/(ASCE)CP.1943-5487.0000172

Zhang, S., Teizer, J., Pradhananga, N., and Eastman, C. M. (2015). Workforce Location Tracking to Model, Visualize and Analyze Workspace Requirements in Building Information Models for Construction Safety Planning. Automation in Construction 60, 74-86. doi:10.1016/j.autcon.2015.09.009

Conflict of Interest: The authors declare that the research was conducted in the absence of any commercial or financial relationships that could be construed as a potential conflict of interest.

Publisher's Note: All claims expressed in this article are solely those of the authors and do not necessarily represent those of their affiliated organizations, or those of the publisher, the editors and the reviewers. Any product that may be evaluated in this article, or claim that may be made by its manufacturer, is not guaranteed or endorsed by the publisher.

Copyright (C) 2022 Nakanishi, Kaneta and Nishino. This is an open-access article distributed under the terms of the Creative Commons Attribution License (CC BY). The use, distribution or reproduction in other forums is permitted, provided the original author(s) and the copyright owner(s) are credited and that the original publication in this journal is cited, in accordance with accepted academic practice. No use, distribution or reproduction is permitted which does not comply with these terms. 